\title{
Employment status and desire for work in severe mental illness: results from an observational, cross-sectional study
}

\author{
Uta Gühne ${ }^{1}$ (D) Alexander Pabst ${ }^{1} \cdot$ Margrit Löbner $^{1} \cdot$ Johanna Breilmann $^{2} \cdot$ Alkomiet Hasan $^{3} \cdot$ Peter Falkai $^{4}$. \\ Reinhold Kilian ${ }^{2} \cdot$ Andreas Allgöwer $^{5} \cdot$ Klemens Ajayi $^{6} \cdot$ Jessica Baumgärtner ${ }^{3} \cdot$ Peter Brieger $^{6} \cdot$ Karel Frasch $^{2,7}$. \\ Stephan Heres ${ }^{6}$. Markus Jäger ${ }^{2,8}$. Andreas Küthmann ${ }^{9}$. Albert Putzhammer ${ }^{10}$ - Bertram Schneeweiß ${ }^{6}$. \\ Michael Schwarz ${ }^{6}$. Thomas Becker ${ }^{2} \cdot$ Markus Kösters $^{2}$ · Steffi G. Riedel-Heller ${ }^{1}$
}

Received: 19 August 2020 / Accepted: 7 April 2021 / Published online: 16 April 2021

(c) The Author(s) 2021

\begin{abstract}
Purpose People with a severe mental illness (SMI) are at particular risk of occupational exclusion. Among the approaches to occupational rehabilitation, supported employment (SE) has been proven to be the most effective. A requirement to enter SE-programs is that individuals must want to seek competitive employment. The aim of this work is to investigate the relationship between serious mental illness and the desire to work including potential predictors.

Methods This is a cross-sectional observational study of patients with SMI aged 18-65 years $(n=397)$. Patients were interviewed by trained staff using standardised instruments. The relationship between potential predictors and a strong preference for employment were analysed using a hierarchic binary logistic regression model.

Results Only about one-quarter (27.9\%) of SMI patients is in competitive employment. Another quarter is unemployed (25.9\%). Results show that the desire for competitive employment is strong among more than half of the SMI patients. Among the unemployed, two-thirds express a strong desire for work. These individuals are an ideal target group for SE interventions. Comorbid chronic physical illness, diagnosis, and the subjectively judged ability to work are associated with the desire for work.

Conclusion Our data confirm a substantial exclusion of individuals with SMI from the workforce. In general, care needs for workplace interventions are not being met and leave much room for improvement. In addition to employment status, the desire for work should be routinely assessed.

Study registration The study was registered in the German Clinical Trials Register (DRKS) (https://www.drks.de/drks web/navigate.do?navigationId=trial.HTML\&TRIAL_ID=DRKS00015801) and under the WHO-Platform "International Clinical Trials Registry Platform" (ICTRP) (https://apps. who.int/trialsearch/Trial2.aspx?TrialID=DRKS00015801) under the registration number DRKS00015801 before the start of recruitment (Registration date: 21.02.2019).
\end{abstract}

Keywords Employment status $\cdot$ Desire to work $\cdot$ Supported employment $\cdot$ Predictors $\cdot$ Work ability

Markus Kösters, SteffiG. Riedel-Heller shared last authorship.

Uta Gühne

Uta.Guehne@medizin.uni-leipzig.de

1 Medical Faculty, Institute of Social Medicine, Occupational Health and Public Health (ISAP), University of Leipzig, Philipp-Rosenthal-Straße 55, 04103 Leipzig, Germany

2 Department of Psychiatry II, Ulm University, BKH Günzburg, Günzburg, Germany

3 Department of Psychiatry, Psychotherapy and Psychosomatic, Medical Faculty, University of Augsburg, BKH Augsburg, Augsburg, Germany
4 Department of Psychiatry and Psychotherapy, University Hospital Munich, Munich, Germany

5 Institute for Epidemiology and Medical Biometry, Ulm University, Ulm, Germany

6 Kbo-Isar-Amper Hospital, Munich, Germany

7 District Hospital Donauwörth, Donauwörth, Germany

8 District Hospital Kempten, Kempten, Germany

9 District Hospital Memmingen, Memmingen, Germany

10 District Hospital Kaufbeuren, Kaufbeuren, Germany 


\section{Background}

Mental disorders are associated with negative effects on employment for those affected. It is assumed that patients with a severe mental illness (SMI) are at particular risk of occupational exclusion [1-3]. However, data on the work status of severely mentally ill people are scarce [4].

A literature review from 2004 showed that in Europe, only $10-20 \%$ of patients suffering from schizophrenia were employed [5]. An Italian study found that the employment rate in patients with SMI is significantly lower as compared to non-SMI patients (Employed: 6\% vs. 39\%, $p<0.001$ ) [6]. A more recent German study of a large, unselected sample of patients undergoing inpatient psychiatric treatment $(n=815)$ found that only $21 \%$ had a permanent employment contract. Many of them did not return to their workplace after being discharged [7]. In Germany, retirement due to disability from mental disorders has risen steadily in recent years. In 2016, $43 \%$ of early retirements were related to mental disorders [8]. Furthermore, the number of mentally ill people working in sheltered workshops has been steadily increasing over the last decades. Currently, the proportion of mentally ill people among all those employed in sheltered workshops is $20 \%$. This corresponds to about 60,000 people with severe disabilities due to mental illness [9].

Although Germany offers a range of different vocational rehabilitation programs for mentally ill individuals [10], exclusion from the workforce is still high [11]. Most of the German rehabilitative services follow the principle: "first train-then place". However, supported employment (SE) initiatives, especially Individual Placement and Support (IPS) programmes [12], are evolving [13]. There is profound evidence in favour of SE [14-16]. In addition to positive effects on employment rates and job retention, positive effects on non-vocational outcomes, such as reduced need for inpatient treatment, reduced psychopathological symptoms, and improved quality of life were reported [17-20]. Therefore, SE is strongly recommended in the German S3 guideline, "Psychosocial therapies for severe mental illness" as the most effective intervention for bringing individuals with SMI back to employment [21]. A requirement to enter an SE-program is the individual's preference for competitive employment. However, data on the preferences of severely mentally ill people regarding employment are rare and predictors of those preferences have not been studied so far. Therefore, to identify potential target groups for SE-interventions, this study aims to answer the following questions: (1) how strong is the current desire for competitive employment among patients with SMI? (2) What is the current employment situation and how does it relate to the desire to work? (3) What sociodemographic, illness-related and other relevant individual characteristics are associated with a strong preference for work?

\section{Methods}

\section{Design and setting}

This study is a non-interventional, cross-sectional study of patients with SMI conducted within a larger project (Implementation Status of the German Guideline for Psychosocial Interventions for Patients with Severe Mental Illness (IMPPETUS)) [22]. The data were collected in 10 departments of psychiatry and psychotherapy, which provide in- and outpatient psychiatric care for people with mental illnesses in Bavaria (Upper Bavaria and Swabia), including metropolitan catchment areas (Augsburg and Munich), middle-urban regions (Kempten and Memmingen) and rural regions (Donauwoerth, Guenzburg, Kaufbeuren, and Taufkirchen). Recruitment and data collection were carried out from March 2019 to September 2019. The participants were interviewed during their inpatient or day-hospital stay.

\section{Participants}

A total of 878 patients were initially contacted to participate in the study. Of these, 471 were interested in participating and were screened and 458 patients met the inclusion criteria and agreed to participate. Data were collected from 398 patients. Data could not be gathered from 60 subjects, since they were no longer reachable, had cancelled participation or had other reasons for discontinuation. The analyses were carried out with the data from 383 patients; one patient was excluded from the analyses, because it became apparent afterwards that he did not meet the inclusion criteria (18-65 years). For 14 patients, there were no data available on their desire for work. For nine patients, only the fulfilment of the inclusion criteria was documented, but concrete values are missing for $\operatorname{GAF}(n=7)$ or age $(n=2)$. For further details, see Fig. 1.

\section{Screening and inclusion of participants}

Patients were invited by study personnel to participate in the study. Patients who agreed were screened using the "Global Assessment of Functioning" (GAF) [23] and the German version of the "Health of the Nation Outcome Scales" (HoNOS) [24] by trained staff to identify patients with SMI. The HoNOS-D is a 12-item instrument for recording the differentiated severity of a mental illness [25]. The GAF records the general level of functioning taking into account psychological, social and professional aspects of patients 
Fig. 1 Flow chart of the included patients

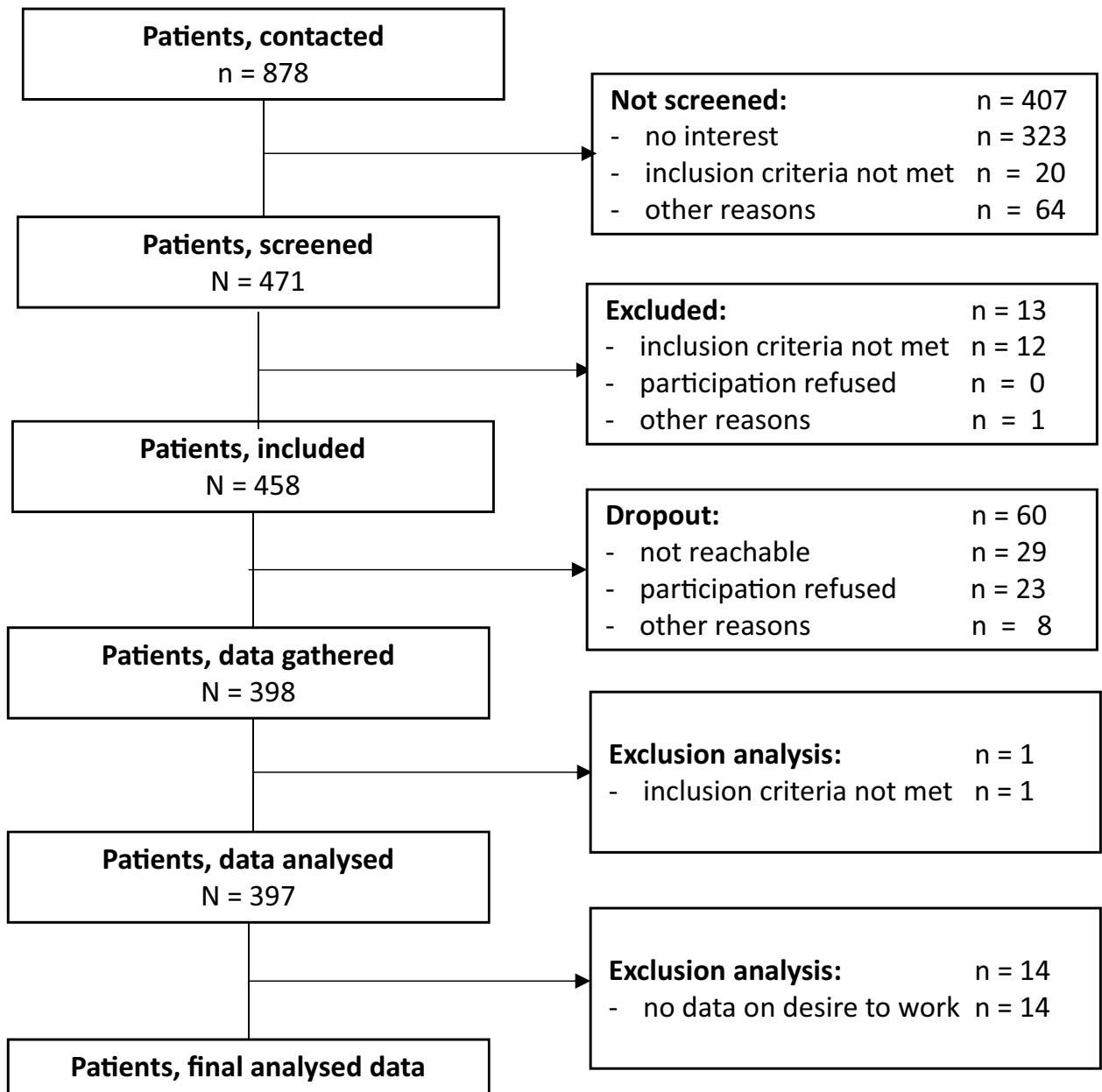

$\mathrm{N}=383$ with mental disorders [23]. The assessment of the degree of severity of functional impairment is made on a scale of 1-100, with a value of 100-91 reflecting excellent performance and a value of 10-1 reflecting very severely impaired performance. The screening was carried out as soon as possible after admission. The duration of the illness was taken from the medical record or from the information provided by the treating physician.

To identify patients with SMI, the following inclusion criteria were used: (I) patients with schizophrenia, schizotypal and delusional disorders (ICD-10 F2x) and affective disorders (ICD-10 F3x); (II) duration of psychiatric illness $\geq 2$ years; and (III) considerable consequences for the activities of daily life and social functioning [21]. The following thresholds were applied to operationalize (III): (1) Global Assessment of Functioning (GAF) [23] from $\leq 60$ and (2) Health of the Nation Outcome Scales (HoNOS) [24] score of (a) $\geq 2$ on one of the items of the symptomatic problems subscale (scores 6,7 and 8 ) and a score of $\geq 2$ on each of the four items of the social problems subscale (scores 9, 10, 11, and 12), or (b) a score of $\geq 3$ on at least one of these items $(9,10,11$, or 12). Further inclusion criteria were: (IV) 18-65 years, (V) ability to consent, and (VI) German language sufficient to understand the questions. Legal representatives of the patients (if any) were informed about participation in the study, if the patient had consented. Patients who met the inclusion criteria were interviewed by the trained study staff shortly before their discharge.

\section{Variables}

\section{Outcome variable}

Information on the desire for paid/competitive employment stems from one item of the questionnaire, "Attitudes and Knowledge Regarding Psychosocial Therapies" developed by the authors and available on request. Respondents were asked: "How strong is your current desire for paid employment in the general labour market?" (answer categories: low, medium, or strong). For reasons of evaluation, responses on low and medium categories were collapsed into one group, 
forming a binary indicator of strong desire for paid/competitive employment (yes/no).

\section{Determinants}

Socio-demographic data, medical data (e.g., diagnosis of psychiatric disorder, age at first mental problems, and presence of a chronic physical illness), and employment-related data of the patients were assessed with items taken from the "Measure of participation and social inclusion for use in people with a chronic mental disorder" (F-INK) [26] and the "Client sociodemographic and service receipt inventory" (CSSRI) [27]. The F-INK is a modular questionnaire with nine modules, which covers the key dimensions of social inclusion. The CSSRI is a semi-structured interview to collect social and demographic data, detailed information on treatment, physician visits, and the use of social and health services. If the respondent or one of his/her parents was born abroad, the respondent was categorized as an immigrant. Patients living alone were distinguished from those not currently alone (with partner, children, parents, siblings, and other relatives, with friends or others).

Questions regarding the knowledge about SE and additional training at the workplace (e.g., social skills training, job-related training, and cognitive training) stem from items of the Questionnaire "Attitudes and Knowledge Regarding Psychosocial Therapies" (yes/no). The current ability to work compared to the best ability to work ever achieved was surveyed with WAI 1 [28]. WAI 1 consists of the single item, "Assume that your work ability at its best has a value of 10 points. How many points would you give your current work ability?" $(0=$ Completely unable to work, $10=$ Work ability at its best).

\section{Analyses}

Absolute and relative frequencies, means and SDs were calculated as descriptive statistics. Group comparisons between strong and non-strong desire for paid employment were calculated using Chi-square tests for categorical variables and Wilcoxon two-sample tests for continuous variables. The relationship of determinants (e.g., age, gender, diagnosis) with a strong preference for paid employment was analysed using hierarchical binary logistic regression models. The analyses followed a blockwise modelling approach. Model 1 assessed the association between sociodemographic factors and a strong preference for competitive employment. Model 2 additionally quantified the impact of illness-related factors. Finally, model 3 additionally assessed the contribution of subjective work-related factors. The blockwise modelling allowed us to quantify the extent to which the effect of single determinants increased/decreased by adding further covariables. Wald $\chi^{2}$ statistics are used to test the significance of predictor variables in the models. Data were missing for $<10 \%$ of all covariates and handled by casewise deletion, since sensitivity analysis revealed no indication of systematic biases due to missing data. The corresponding sample sizes for each subgroup comparison are reported in the tables. All statistical analyses were performed using Stata 15.1 MP (StataCorp LP, College Station, TX) and IBM SPSS Statistics for Windows, version 24 (IBM Corp., Armonk. NY).

\section{Results}

In total, 383 patients with a mean age of 42.7 years (SD 13.1 years) were included in the analysis. More than half of the respondents were women $(n=215,56.1 \%)$. Similarly, more than half of participants were single $(n=215,56.2 \%)$; 158 patients $(41.9 \%)$ lived alone. Seventy patients (18.4\%) stated that they or a parent were born in another country. The majority of patients had a diagnosis of depression $(n=227$, $59.3 \%$ ), almost one-third of patients had a schizophrenia spectrum disorder $(n=118,30.8 \%)$, and almost one-tenth had a bipolar disorder $(n=38,9.9 \%)$. The psychosocial impairments were considerable (GAF, means (SD): 42.3 (9.8)) corresponding to severe disease impairment according to linkage analyses [29]. Half of the respondents reported comorbid physical diseases $(n=192,50.4 \%)$. Work ability (WAI 1) was given an average rating of 4.0 (SD 2.7). Further characteristics of the study participants are shown in Table 1.

\section{Employment status and desire for work}

The majority of patients indicated a strong preference for competitive employment $(n=229,59.8 \%)$. Another 87 patients $(22.7 \%)$ stated a low preference, and 67 patients (17.5\%) a moderate preference (Fig. 2).

Employment information was available for 348 patients. 97 patients (27.9\%) were competitively employed. 90 patients $(25.9 \%)$ surveyed were without employment and seven patients $(2.0 \%)$ were marginally employed. In addition, 17 patients (4.9\%) were engaged in sheltered activities, 81 patients $(23.3 \%)$ had retired for health reasons and 24 patients $(6.9 \%)$ were enrolled in school, vocational training or university. Finally, 32 patients $(9.2 \%)$ stated that they were drawing retirement pensions, looking after children or running a household (Table 2).

Patients competitively employed were significantly more likely to have a strong preference for employment compared to others $(79.4 \%$ vs. $20.6 \%, p<0.001)$. Patients in early retirement were significantly less likely than others to indicate a strong preference for work $(32.1 \%$ vs. $67.9 \%$, $p<0.001)$. There were no significant differences between the 
Table 1 Sociodemographic, clinical and other characteristics of study participants according to their preference for competitive work $(n=383$ )

\begin{tabular}{|c|c|c|c|c|}
\hline & \multirow{2}{*}{$\begin{array}{l}\text { All patients } \\
n=383\end{array}$} & \multicolumn{2}{|c|}{ Strong desire for competitive work } & \multirow{2}{*}{$\begin{array}{l}\text { Value } \\
\text { Wilcoxon two-sample test// } \\
\text { Chi-square test (Pearson) } \\
\text { (df) }\end{array}$} \\
\hline & & $\begin{array}{l}\text { No } \\
n=154(40.2)\end{array}$ & $\begin{array}{l}\text { Yes } \\
n=229(59.8)\end{array}$ & \\
\hline Age (years), mean (SD) $(n=381)$ & $42.7(13.1)$ & $44.3(13.2)$ & $41.6(12.9)$ & $z=1.97^{*}$ \\
\hline \multicolumn{4}{|l|}{ Sex, $n(\%)$} & $\chi^{2}=6.95(1)^{* *}$ \\
\hline Male & $168(43.9)$ & $55(35.7)$ & $113(49.3)$ & \\
\hline Female & $215(56.1)$ & $99(64.3)$ & $116(50.7)$ & \\
\hline \multicolumn{4}{|l|}{ Education, $n(\%)(n=382)$} & $\chi^{2}=2.43(2)$ \\
\hline Low & $146(38.2)$ & $60(39.0)$ & $86(37.7)$ & \\
\hline Medium & $111(29.1)$ & $50(32.5)$ & $61(26.8)$ & \\
\hline High & $125(32.7)$ & $44(28.5)$ & $81(35.5)$ & \\
\hline \multicolumn{4}{|l|}{ Marital status, $n(\%)$} & $\chi^{2}=0.38(2)$ \\
\hline Single & $215(56.2)$ & $84(54.5)$ & $131(57.2)$ & \\
\hline Married/registered partnership & $89(23.2)$ & $36(23.4)$ & $53(23.1)$ & \\
\hline Divorced/widowed/separated & $79(20.6)$ & $34(22.1)$ & $45(19.7)$ & \\
\hline \multicolumn{4}{|l|}{ Living situation $^{\mathrm{a}}, n(\%)(n=377)$} & $\chi^{2}=0.24(2)$ \\
\hline Alone & $158(41.9)$ & $66(43.4)$ & $92(40.9)$ & \\
\hline Not alone & $219(58.1)$ & $86(56.6)$ & $133(59.1)$ & \\
\hline \multicolumn{4}{|l|}{ Immigration background, $n(\%)(n=381)$} & $\chi^{2}=0.61(1)$ \\
\hline No & $311(81.6)$ & $122(79.7)$ & $189(82.9)$ & \\
\hline Yes & $70(18.4)$ & $31(20.3)$ & $39(17.1)$ & \\
\hline \multicolumn{4}{|l|}{ Mental disorder, $n(\%)$} & $\chi^{2}=5.83(2)$ \\
\hline $\mathrm{F} 2 \mathrm{x}$ & $118(30.8)$ & $56(36.4)$ & $62(27.1)$ & \\
\hline F32, F33 & $227(59.3)$ & $88(57.1)$ & $139(60.7)$ & \\
\hline F30, F31 & $38(9.9)$ & $10(6.5)$ & $28(12.2)$ & \\
\hline GAF, means (SD) $(n=376)$ & $42.3(9.8)$ & $40.6(10.1)$ & $43.4(9.4)$ & $z=-2.74 * *$ \\
\hline HoNOS-D, mean (SD) & $21.8(6.0)$ & $22.6(5.8)$ & $21.2(6.0)$ & $z=2.53 *$ \\
\hline $\begin{array}{l}\text { Age at first mental problems (years), mean } \\
\text { (SD) }(n=359)\end{array}$ & $26.8(13.0)$ & $27.2(12.7)$ & $26.6(13.2)$ & $z=0.44$ \\
\hline \multicolumn{4}{|l|}{ Physical illness, $n(\%)(n=381)$} & $\chi^{2}=12.47(1)^{* * *}$ \\
\hline Yes & $192(50.4)$ & $94(61.4)$ & $98(43.0)$ & \\
\hline No & $189(49.6)$ & $59(38.6)$ & $130(57.0)$ & \\
\hline \multicolumn{5}{|c|}{ Knowledge of vocational rehabilitation measures, $n(\%)(n=382)$} \\
\hline Supported employment, Yes & $115(30.1)$ & $41(26.6)$ & $74(32.5)$ & $\chi^{2}=1.49(1)$ \\
\hline Additional training ${ }^{\mathrm{b}}$, Yes & $146(38.2)$ & $52(33.8)$ & $94(41.2)$ & $\chi^{2}=2.17(1)$ \\
\hline Work ability, mean (SD) $(n=379)$ & $4.0(2.7)$ & $3.0(2.3)$ & $4.7(2.8)$ & $z=-5.88 * * *$ \\
\hline
\end{tabular}

Subsample sizes vary due to missing information. Corresponding sizes for variables with missing data are given in brackets

GAF Global assessment of functioning, HoNOS-D German Version of the Health of the Nation Outcome Scales, $S D$ standard deviation, $F 2 x$ Schizophrenia, schizotypic and delusional disorders, F32, F33 Depressive disorders, F30, F31 Mania and bipolar disorder

${ }^{*} p<0.05$

$* * p<0.01$

$* * * p<0.001$

${ }^{\mathrm{a}}$ In terms of a social component

be.g., social skills training, job-related training, cognitive training

two groups in terms of unemployment and sheltered employment (Table 2).

With regard to the group of patients with strong employment preference, slightly more than one-third of patients surveyed were competitively employed $(n=77$,
$38.1 \%)$. Nevertheless, a considerable proportion of those surveyed were unemployed $(n=59,29.2 \%)$, in sheltered employment $(n=9,4.4 \%)$ or retired due to health problems $(n=26,12.9 \%)$ expressed a strong desire for a job in the general labour market. This also applies to some 
Fig. 2 Proportion of respondents with a low, moderate and strong preference for employment in the general labour market

Table 2 Description of the current work situation $(n=348)$

\section{Preference for employment}

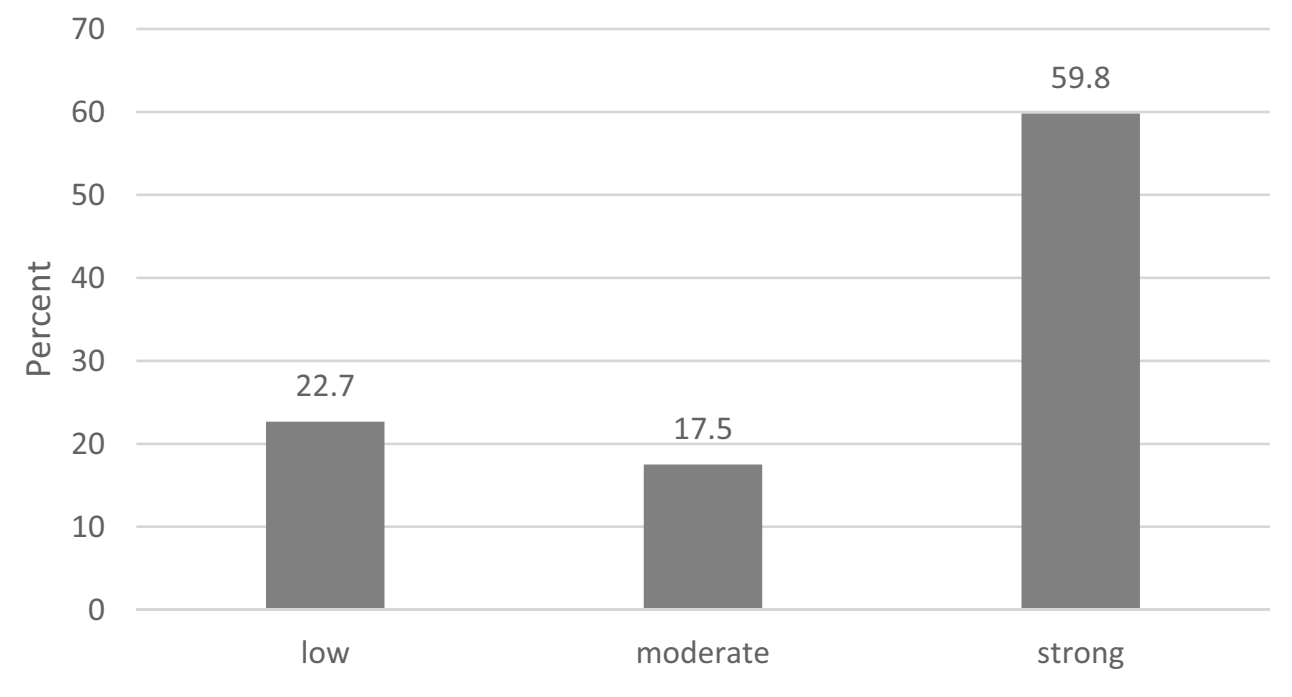

\begin{tabular}{|c|c|c|c|c|c|c|c|c|}
\hline & \multirow{3}{*}{$\begin{array}{l}\text { All patients } \\
n=348 \\
n(\%)^{2}\end{array}$} & \multicolumn{6}{|c|}{$\begin{array}{l}\text { Strong desire to work in general } \\
\text { labour market }\end{array}$} & \multirow{3}{*}{$\begin{array}{l}\text { Value } \\
\text { Chi-square test } \\
\text { (Pearson) (df) }\end{array}$} \\
\hline & & \multicolumn{3}{|c|}{$\begin{array}{l}\text { No } \\
n=146(42.0 \%)\end{array}$} & \multicolumn{3}{|c|}{$\begin{array}{l}\text { Yes } \\
n=202(58.0 \%)\end{array}$} & \\
\hline & & $N$ & $\%^{2}$ & $\%^{3}$ & $N$ & $\%^{2}$ & $\%^{3}$ & \\
\hline \multicolumn{9}{|l|}{ Vocational situation, $n(\%)$} \\
\hline Employed, general labour market & 97 (27.9) & 20 & 13.7 & 20.6 & 77 & 38.1 & 79.4 & $22.94(1) * * *$ \\
\hline Sheltered employed & $17(4.9)$ & 8 & 5.5 & 47.1 & 9 & 4.4 & 52.9 & $0.26(1)$ \\
\hline Marginally employed & $7(2.0)$ & 3 & 2.0 & 42.9 & 4 & 2.0 & 57.1 & -1 \\
\hline Unemployed & $90(25.9)$ & 31 & 21.2 & 34.4 & 59 & 29.2 & 65.6 & $2.21(1)$ \\
\hline Early retired & $81(23.3)$ & 55 & 37.7 & 67.9 & 26 & 12.9 & 32.1 & $30.73(1) * * *$ \\
\hline In school, education, or study & $24(6.9)$ & 9 & 6.2 & 37.5 & 15 & 7.4 & 62.5 & $-{ }^{1}$ \\
\hline $\begin{array}{l}\text { Parental leave, retirement pension } \\
\text { or housekeeping }\end{array}$ & $32(9.2)$ & 20 & 13.7 & 62.5 & 12 & 6.0 & 37.5 & $-{ }^{1}$ \\
\hline \multicolumn{9}{|l|}{$* p<0.05$} \\
\hline \multicolumn{9}{|l|}{$* * p<0.01$} \\
\hline \multicolumn{9}{|l|}{$* * * p<0.001$} \\
\hline \multirow{2}{*}{\multicolumn{9}{|c|}{$\begin{array}{l}{ }^{1} \text { Differences were not examined, because the number in individual cells was too small or irrelevant i } \\
\text { terms of content } \\
{ }^{2} \text { Relative frequencies over column }\end{array}$}} \\
\hline & & & & & & & & \\
\hline \multicolumn{9}{|l|}{${ }^{3}$ Relative frequencies over rows } \\
\hline
\end{tabular}

of the respondents who were in marginal employment, in training or at home (Table 2).

Looking explicitly at the group of patients without a current job (e.g., those unemployed), two-thirds ( $n=59$, $65.6 \%$ ) expressed a strong desire to work in the general labour market. Accordingly, only one-third of the currently unemployed did not do so (Table 2).

\section{Predictors of a strong preference for competitive employment}

Table 1 provides an overview of the differences between the patients with strong preference for competitive employment compared to those without a strong preference. With regard to sociodemographic variables, the results show that patients 
with strong preference are younger $(p=0.048)$ and more likely to be men $(p=0.008)$. No differences were observed with regard to education, marital status, living situation, and immigration. In terms of illness, the results indicate greater psychosocial impairment (GAF, $p=0.006)$, a higher severity of mental disorder (HoNOS-D, $p=0.011$ ) and a higher proportion of additional chronic physical illnesses $(p<0.001)$ in the group containing individuals with a low or moderate desire to work. The specific diagnosis of mental illness and the age at which the first mental problems occurred did not differ significantly between the two groups. Patients with a strong desire for work rated their current ability to work significantly better $(p<0.001)$.

For binary logistic regression analysis $(n=342$ cases with complete data), three models are shown in Table 3, investigating sociodemographic, illness-related, and work-related variables with a strong desire for paid employment. Model 1 revealed that male gender increased the likelihood of a strong preference for competitive employment $(\mathrm{OR}=1.81[95 \%$ CI 1.17-2.80], $p=0.007)$. The comparison of model 1 with models 2 and 3 showed that this association became insignificant when additional illness- and work-related factors

Table 3 Social, health and work related determinants for strong preference for competitive work in patients with SMI $(n=342)$ : results of hierarchical binary logistic regression analyses

\begin{tabular}{|c|c|c|c|c|c|c|c|c|c|c|}
\hline \multirow[t]{2}{*}{ Indicator variable } & \multirow[t]{2}{*}{ Category } & \multicolumn{3}{|c|}{$\begin{array}{l}\text { Model 1 } \\
(n=373)\end{array}$} & \multicolumn{3}{|c|}{$\begin{array}{l}\text { Model } 2 \\
(n=344)\end{array}$} & \multicolumn{3}{|l|}{$\begin{array}{l}\text { Model } 3 \\
(n=342)\end{array}$} \\
\hline & & OR & $95 \% \mathrm{CI}$ & & OR & $95 \% \mathrm{CI}$ & & OR & $95 \% \mathrm{CI}$ & \\
\hline \multirow[t]{2}{*}{ Gender } & Female & Ref & & & & & & & & \\
\hline & Male & $1.81 * *$ & 1.17 & 2.80 & 1.55 & 0.96 & 2.49 & 1.53 & 0.93 & 2.50 \\
\hline Age & & 0.98 & 0.96 & 1.00 & 0.99 & 0.96 & 1.01 & 0.99 & 0.96 & 1.02 \\
\hline \multirow[t]{3}{*}{ Education } & Low & Ref & $\chi^{2}=1.96$ & & & $\chi^{2}=2.44$ & & & $\chi^{2}=2.07$ & \\
\hline & Medium & 0.97 & 0.58 & 1.63 & 0.82 & 0.47 & 1.45 & 0.89 & 0.49 & 1.63 \\
\hline & High & 1.38 & 0.82 & 2.32 & 1.31 & 0.74 & 2.30 & 1.37 & 0.76 & 2.48 \\
\hline \multirow[t]{3}{*}{ Marital status } & Single & Ref & $\chi^{2}=1.65$ & & & $\chi^{2}=0.12$ & & & $\chi^{2}=0.64$ & \\
\hline & Married & 1.43 & 0.74 & 2.75 & 1.08 & 0.51 & 2.32 & 1.33 & 0.60 & 2.92 \\
\hline & $\begin{array}{l}\text { Divorced/ } \\
\text { widowed/sepa- } \\
\text { rated }\end{array}$ & 1.44 & 0.76 & 2.73 & 1.13 & 0.57 & 2.24 & 1.27 & 0.63 & 2.57 \\
\hline \multirow[t]{2}{*}{ Living situation $^{\mathrm{a}}$} & Alone & Ref & & & & & & & & \\
\hline & Not alone & 1.06 & 0.65 & 1.74 & 1.03 & 0.60 & 1.75 & 0.95 & 0.54 & 1.67 \\
\hline \multirow[t]{2}{*}{ Migration background } & No & Ref & & & & & & & & \\
\hline & Yes & 0.76 & 0.44 & 1.32 & 0.96 & 0.52 & 1.79 & 0.80 & 0.41 & 1.55 \\
\hline \multirow[t]{3}{*}{ Mental disorder } & $\mathrm{F} 2 \mathrm{x}$ & & & & Ref & $\chi^{2}=5.56$ & & & $\chi^{2}=6.37 *$ & \\
\hline & F32, F33 & & & & 1.24 & 0.72 & 2.14 & 1.55 & 0.88 & 2.75 \\
\hline & F30, F31 & & & & $2.99 *$ & 1.20 & 7.46 & $3.53 *$ & 1.30 & 9.60 \\
\hline Age at first problems & & & & & 1.00 & 0.98 & 1.03 & 1.00 & 0.97 & 1.02 \\
\hline GAF & & & & & 1.02 & 1.00 & 1.05 & 1.01 & 0.99 & 1.04 \\
\hline HoNOS-D & & & & & 0.99 & 0.94 & 1.03 & 1.01 & 0.96 & 1.05 \\
\hline \multirow[t]{2}{*}{ Physical illness } & No & & & & Ref & & & & & \\
\hline & Yes & & & & $0.48 * *$ & 0.30 & 0.79 & $0.58 *$ & 0.35 & 0.97 \\
\hline \multirow[t]{2}{*}{ Knowledge, SE } & No & & & & & & & Ref & & \\
\hline & Yes & & & & & & & 1.50 & 0.85 & 2.64 \\
\hline \multirow[t]{2}{*}{ Knowledge, additionnal training } & No & & & & & & & Ref & & \\
\hline & Yes & & & & & & & 1.05 & 0.62 & 1.79 \\
\hline \multirow[t]{2}{*}{ Work ability } & & & & & & & & $1.25 * * *$ & 1.14 & 1.38 \\
\hline & $\mathrm{R}^{2}$ (McFadden) & 0.028 & & & 0.071 & & & 0.123 & & \\
\hline
\end{tabular}

$\chi^{2}$ indicating the significance of the predictor variable in the models by wald test

$S E$ Supported Employment, GAF Global assessment of functioning, HoNOS-D German Version of the Health of the Nation Outcome Scales, F2 $x$ Schizophrenia, schizotypic and delusional disorders, F32, F33 Depressive disorders, F30, F31 Mania and bipolar disorder, OR Odds ratio, CI Confidence interval

Boldface indicates statistical significance: $* p<0.05, * * p<0.01, * * * p<0.001$

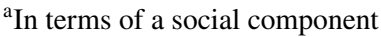


were considered. Model 2 indicated that chronic physical illness was significantly associated with a preference for competitive employment, adjusting for sociodemographics. The presence of a comorbid chronic physical illness compared to a status free of chronic physical illness reduced the odds ratio of respondents stating a strong preference by almost $50 \%(\mathrm{OR}=0.48$ [95\% CI 0.30-0.79], $p=0.004)$. In addition, when work-related predictors were included in model 3 , the negative association between comorbid chronic physical diseases and a strong desire for paid employment was still significant $(\mathrm{OR}=0.58$ [95\% CI 0.35-0.97], $p=0.039)$. Model 3 also showed an increase of the odds ratio of a strong preference for patients with bipolar disorder as compared to patients with schizophrenic disorder $(\mathrm{OR}=3.53[95 \%$ CI 1.30-9.60], $p=0.013$ ). In model 3 , knowledge of vocational rehabilitation measures had no significant effect, but the likelihood of a preference for competitive employment increased significantly with a higher subjective work ability $(\mathrm{OR}=1.25$ [95\% CI 1.14-1.38], $p<0.001)$.

\section{Discussion}

\section{Employment status and desire for work}

Our data confirm a substantial exclusion of individuals suffering SMI from the workforce. Just over half of the patients surveyed reported being unemployed, retired early due to mental illness, or in sheltered employment. Only one-quarter (27\%) of the SMI patients is engaged in competitive employment. However, a desire for competitive employment is highly ranked with more than half of the SMI patients having a strong preference for employment in the general labour market. Of patients in the subgroup, currently unemployed, $65 \%$ endorsed a strong preference for competitive employment. This is of utmost importance, since a high interest in work increases the likelihood of future employment [30, 31]. On the other hand, lack of motivation was found to be one of the most significant barriers to re-entering workforce $[32,33]$.

Few studies have investigated the desire for competitive work. Westscott et al. (2015) showed that $34 \%$ of community-based patients with a diagnosis of schizophrenia or schizoaffective disorder $(n=255)$ were currently employed and an additional $51 \%$ were interested in employment. In total, $85 \%$ were already participating in, or interested in, employment [34]. In another community-based sample of persons with SMI $(n=166), 30 \%$ of the participants expressed no interest in getting a job [35]. In a recent study examining a German sample of inpatients comparable to our sample, $71 \%$ of the participants stated a short- or mediumterm interest in work or training/study [36]. In contrast, the proportion of inpatients with a strong desire to work was estimated to be significantly lower in a Belgian study. A set of multiple-response questions asked patients to indicate their short- and long-term vocational goals, including competitive employment. In the short term, $35.5 \%$ of the patients preferred competitive employment and $21.8 \%$ preferred voluntary work. A similar picture emerged when considering long term goals with $44.6 \%$ preferring competitive employment and $14.6 \%$ opting for voluntary employment. Patients from long-term wards were included in this sample [37]. Mueser et al. examined 528 patients with schizophrenia who had had a psychiatric hospitalisation or symptom exacerbation in the past 3 months. Among patients who were not competitively employed, $61 \%$ reported an interest in working [30]. Although the results are heterogenous, most of the studies reported quite a substantial number of patients with SMI having a strong desire for work. Differences may be attributed to variations in patient samples and the wording of the questions asked to inquire about desire for work.

Our findings point to the need for targeted job-related interventions among patients with SMI. Two-thirds of individuals who are currently unemployed expressed a high desire for work and, therefore, constitute an obvious target group for SE interventions. The basic principles of SE and Individual Placement and Support include a focus on competitive employment based on user preference. The approach was tailored for severely mentally ill people and has been proven effective in numerous studies [14]. Users are supported through individualised and long-term on-the-job support (job coaching), while mental health and employment services are closely integrated [12]. The need for appropriate support is not currently being met in Germany. A recent study showed that $71 \%$ of patients not working or enrolled in an educational program indicated that "work" was a relevant topic. Specifically, $63 \%$ would like vocational support; of these, $84 \%$ would participate in job coaching. Young adults (77\%) and first-time sufferers (73\%) indicated an even higher need for support [36].

Interventions are also required for other groups who would like to make the step to a competitive employment such as people who have retired due to health problems or those who are in sheltered employment with high desire to do more. In fact, almost one-third of the respondents in early retirement $(32 \%)$ and more than half of the respondents in sheltered employment (53\%) affirmed a strong desire for competitive work. Similarly, patients who have a rather low interest in work or who are ambivalent should receive interventions to increase interest and motivation. Attitudes of mental health professionals towards their patients and the social environment are important, as interest in work can be altered not only by one's own expectations, but also by the expectations of others. Healthcare professionals, in particular, can reinforce negative expectations if they do not consistently address work-life and return-to-work issues [34]. It 
is beneficial to promote patients' confidence and self-esteem [38].

\section{Predictors of the desire for work}

Three predictors of a high desire to work have emerged as a result of the present work. Among the disease-related aspects, an additional physical illness seems to have a major influence on the desire to work. The presence of a comorbid chronic physical illness reduced the likelihood that respondents indicated a strong preference by almost $50 \%$. In terms of diagnosis, individuals suffering from bipolar disorder were more likely to express a strong desire to work than patients with a schizophrenia disorder. Patients' self-rated work ability is associated with a stronger desire to work. However, the WAI 1 score level (without strong desire 3.0 [SD: 2.3] vs. with strong desire 4.7 [SD: 2.8 ]) is relatively low in both groups. To our knowledge, this is the first study to examine predictors of desire for competitive work among patients with SMI.

It is possible that the predictors differ from those on the employment status of people with SMI. However, there is also evidence for comparable findings. A study of SE programs in unemployed individuals showed that the presence of a comorbid physical condition was predictive of lower rates of competitive employment, fewer hours worked, and lower wages earned over the 2-year follow-up period [39]. A negative association between somatic comorbidity and employment was also observed in other studies [40, 41]. Other predictors are also discussed in connection with employment in patients with SMI. Some of the findings are considered contradictory. In addition to functioning, sociodemographic factors and work history [5, 30, 42, 43], for example, a connection between stigma and discrimination in the workplace and employment [44] and between the type of vocational rehabilitation measure and work [45] is also described. The low values of the explained variance in our models suggest that further predictors would have an influence on the desire to work.

\section{Limitations}

Although a large sample of SMI patients was investigated, selection bias cannot be ruled out. This holds true in terms of recruitment strategies, as well as in response to the invitation to the study. The results refer only to patients with SMI in the Bavarian region of Germany. We investigated desire for work as a relevant but simple real-life question. It is possible that related, more comprehensive constructs and instruments such as return to work self-efficacy [46] or motivational aspects can provide deeper insights [47]. The data were collected in a cross-sectional study so that co-variations cannot be interpreted causally.

\section{Conclusions}

Employment is considered to be an important determinant of health and a milestone in the recovery process of people with SMI [48]. Our findings show that the desire for competitive work is strong among more than half of patients with SMI. Likewise, exclusion of these patients from the workforce is high. Among the unemployed, two-thirds express a strong desire for work. These individuals comprise a clear target group for SE interventions. There is much room for improvement, because the need for workplace interventions is not adequately met. Mental health professionals must routinely assess both employment status and desire for work. Based on the assumption that the desire for work changes over time and can be modified [49], motivation to work should be strengthened throughout the course of treatment. Attitudes of mental health professionals are relevant, and issues of work-life balance should be addressed throughout the course of treatment. The data also underline the relevance of somatic comorbidity for work-related outcomes. In programmes intended to strengthen labour market integration, it is important to consider the physical health status of patients.

Acknowledgements We specifically thank the members of the IMPPETUS Study Group for their excellent work: Rainer Muche, Michael Bachmaier, Jasmin Buchberger, Theodor Deggendorfer, Lea Eichele, Sarah Fritz, Gabriele Gaigl, Dagmar Gröber-Grätz, Paulo Kling Lourenço, Natalie Lamp, Juliane Lott, Katrin Mayer, Katharina Merz, Susanna Müller-Tischmacher, Ursula Nägele, Jana Nolden, Janine Quittschalle, Iris Schicker, Esther Täumer, Tamara Waldmann, Michael Willi. Above all, we wish to thank all the IMPPETUS study participants.

Author contributions All authors were involved in developing the study design and methods. SRH, UG, and ML conceptualised the analyses. JB and MK oversaw the study implementation and data collection and cleaned and processed the data. UG and AP performed the statistical analysis. UG was responsible for writing the first draft of the manuscript. SRH and ML supervised the analyses and the writing of the manuscript. All authors read, critically revised, and approved the final manuscript.

Funding Open Access funding enabled and organized by Projekt DEAL. This work is funded by the Innovation Committee of the Federal Joint Committee (Gemeinsamer Bundesausschuss, G-BA), Germany, under the grant number 01VSF17017. The funder was not involved in the design of the study, in collection of data, in data analysis or interpretation, and in manuscript writing.

Data availability The data sets used and analysed in the presented analyses are available from the corresponding author on reasonable request.

\section{Declarations}

Conflicts of interest The authors declare that they have no conflicts of interest/competing interests with respect to the research.

Ethical approval The ethics vote was obtained before the start of the study at the ethics committee of the University of Ulm (ref: 463/18). 
There were no ethical objections to the conduct of the study. Furthermore, the study was conducted in accordance with the Declaration of Helsinki.

Consent to participate Study participants were informed about the study via an information sheet and were asked to provide written informed consent to participate.

Consent for publication All participants received a written declaration of consent prior to participation in the study, which also included consent to the publication of anonymous data of individual participants.

Open Access This article is licensed under a Creative Commons Attribution 4.0 International License, which permits use, sharing, adaptation, distribution and reproduction in any medium or format, as long as you give appropriate credit to the original author(s) and the source, provide a link to the Creative Commons licence, and indicate if changes were made. The images or other third party material in this article are included in the article's Creative Commons licence, unless indicated otherwise in a credit line to the material. If material is not included in the article's Creative Commons licence and your intended use is not permitted by statutory regulation or exceeds the permitted use, you will need to obtain permission directly from the copyright holder. To view a copy of this licence, visit http://creativecommons.org/licenses/by/4.0/.

\section{References}

1. Kilian R, Becker T (2007) Macro-economic indicators and labour force participation of people with schizophrenia. J Ment Health $16: 211-222$

2. Gühne U, Becker T, Salize H-J, Riedel-Heller SG (2015) How many people in Germany are seriously mentally ill? Psychiatr Prax 42:415-423. https://doi.org/10.1055/s-0035-1552715

3. Hakulinen C, Elovainio M, Arffman M, Lumme S, Suokas K, Pirkola S, Keskimäki I, Manderbacka K, Böckerman P (2020) Employment status and personal income before and after onset of a severe mental disorder: a case-control study. Psychiatr Serv 71:250-255. https://doi.org/10.1176/appi.ps.201900239

4. Gühne U, Riedel-Heller SG (2015) Die Arbeitssituation von Menschen mit schweren psychischen Erkrankungen in Deutschland. https://www.dgppn.de/_Resources/Persistent/6f086ccalfce87b 992b2514621343930b0c398c5/Expertise_Arbeitssituation_201509-14_fin.pdf. Accessed 17 August 2020

5. Marwaha S, Johnson S (2004) Schizophrenia and employment: a review. Soc Psychiatry Psychiatr Epidemiol 39:337-349. https:// doi.org/10.1007/s00127-004-0762-4

6. Parabiaghi A, Bonetto C, Ruggeri M, Lasalvia M (2006) Severe and persistent mental illness: a useful definition for prioritizing community-based mental health service interventions. Soc Psychiatry Psychiatr Epidemiol 41:457-463. https://doi.org/10.1007/ s00127-006-0048-0

7. Mernyi L, Hölzle P, Hamann J (2018) Psychiatric inpatient treatment and return to work. Psychiatr Prax 45:197-205. https://doi. org/10.1055/s-0043-101901

8. Bund DRV (2018) Rentenversicherung in Zahlen 2017. Deutsche Rentenversicherung, Berlin

9. BAG WfbM (2019) Werkstatt im Wandel. Jahresbericht 2018. https://www.bagwfbm.de/publications. Accessed 1 March 2021

10. Stengler K, Rauschenbach J, Riedel-Heller SG, Becker T, Steinhart I, Gerlinger G, Hauth I (2016) DGPPN compass of participation for vocational integration of persons with mental illnesses. Nervenarzt 87:1144-1151. https://doi.org/10.1007/ s00115-016-0215-9

11. Riedel-Heller S, Gühne U (2015) Work life participation of mentally Ill individuals-implications for research and best practice? Psychother Psych Med 65:383-386. https://doi.org/10.1055/s0035-1559668

12. Drake RE, Bond GR, Becker DR (2012) IPS supported employment: an evidence-based approach to supported employment. Oxford University Press, New York

13. Krasselt A, Stengler K, Steinberg H (2020) Work participation for people with severe mental illnesses: a challenge yesterday and today. Psychiatr Prax 47:273-280. https://doi.org/10. 1055/a-1123-0562

14. Suijkerbuijk YB, Schaafsma FG, van Mechelen JC et al (2017) Interventions for obtaining and maintaining employment in adults with severe mental illness, a network meta-analysis. Cochrane Database Syst Rev. https://doi.org/10.1002/14651858.CD011867. pub2

15. Modini M, Tan L, Brinchmann B et al (2016) Supported employment for people with severe mental illness: systematic review and meta-analysis of the international evidence. Br J Psychiatry 209:14-22. https://doi.org/10.1192/bjp.bp.115.165092

16. Bond GR, Lockett H, Weeghel V (2020) International growth of individual placement and support. Epidemiol Psychiatr Sci 29:e183. https://doi.org/10.1017/S2045796020000955

17. Kukla M, Bond GR, Xie H (2012) A prospective investigation of work and nonvocational outcomes in adults with severe mental illness. J Nerv Ment Dis 200:214-222. https://doi.org/10.1097/ NMD.0b013e318247cb29

18. Kilian R, Lauber C, Kalkan R, Dorn W, Rössler W, Wiersma D, van Buschbach JT, Fioritti A, Tomov T, Catty J, Burns T, Becker $\mathrm{T}$ (2012) The relationships between employment, clinical status, and psychiatric hospitalisation in patients with schizophrenia receiving either IPS or a conventional vocational rehabilitation programme. Soc Psychiatry Psychiatr Epidemiol 47:1381-1389. https://doi.org/10.1007/s00127-011-0451-z

19. Hoffmann H, Jäckel D, Glauser S, Mueser KT, Kupper Z (2014) Long-term effectiveness of supported employment: 5-year followup of a randomized controlled trial. Am J Psychiatry 171:11831190. https://doi.org/10.1176/appi.ajp.2014.13070857

20. Areberg C, Bejerholm U (2013) The effect of IPS on participants' engagement, quality of life, empowerment, and motivation: a randomized controlled trial. Scand J Occup Ther 20:420-428. https:// doi.org/10.3109/11038128.2013.765911

21. Gühne U, Weinmann S, Riedel-Heller SG, Becker T (2019) S3-Leitlinie Psychosoziale Therapien bei schweren psychischen Erkrankungen. S3-Praxisleitlinien in Psychiatrie und Psychotherapie, 2nd edn. Springer, Berlin

22. Breilmann J, Kilian R, Riedel-Heller SG, et al (2018) Protocol for a cross-sectional observational study: Implementation status of the German guideline for psychosocial interventions for patients with severe mental illness (IMPPETUS). https://www.drks.de/ drks_web/navigate.do?navigationId=trial.HTML\&TRIAL_ID $=$ DRKS00015801. Accessed 17 August 2020

23. Jones SH, Thornicroft G, Coffey M, Dunn G (1995) A brief mental health outcome scale-reliability and validity of the Global assessment of functioning (GAF). Br J Psychiatry 166:654-659. https://doi.org/10.1192/bjp.166.5.654

24. Wing JK, Beevor AS, Curtis RH, Park SB, Hadden S, Burns A (1998) Health of the nation outcome scales (HoNOS). Research and development. Br J Psychiatry 172:11-18. https://doi.org/10. 1192/bjp.172.1.11

25. Andreas S, Harfst T, Rabung S, Mestel R, Schauenburg H, Hausberg M, Kawski S, Koch U, Schulz H (2010) The validity of the German version of the Health of the nation outcome scales (HoNOS-D): a clinician-rating for the differential assessment 
of the severity of mental disorders. Int J Methods Psychiatr Res 19:50-62. https://doi.org/10.1002/mpr.305

26. Schützwohl M, Souza PML, Rackel Y (2017) A measure of participation and social inclusion for use in people with a chronic mental disorder (F-INK). Psychiatr Prax 44:65-74. https://doi. org/10.1055/s-0042-102320

27. Roick C, Kilian R, Matschinger H, Bernert S, Mory C, Angermeyer M (2001) German adaptation of the client sociodemographic and service receipt inventory: an instrument for the cost of mental health care. Psychiatr Prax 28(Suppl 2):S84-90. https:// doi.org/10.1055/s-2001-17790

28. Ebener M, Hasselhorn HM (2019) Validation of short measures of work ability for research and employee surveys. Int J Environ Res Public Health 16:3386. https://doi.org/10.3390/ijerph16183386

29. Samara MT, Engel RR, Millier A, Kandenwein J, Toumi M, Leucht S (2014) Equipercentile linking of scales measuring functioning and symptoms: examining the GAF, SOFAS, CGI-S, and PANSS. Eur Neuropsychopharmacol 24:1767-1772. https://doi. org/10.1016/j.euroneuro.2014.08.009

30. Mueser KT, Salyers MP, Mueser PR (2001) A prospective analysis of work in schizophrenia. Schizophr Bull 27:281-296. https://doi. org/10.1093/oxfordjournals.schbul.a006874

31. Reddy LF, Llerena K, Kern RS (2016) Predictors of employment in schizophrenia: the importance of intrinsic and extrinsic motivation. Schizophr Res 176:462-466. https://doi.org/10.1016/j.schres. 2016.08.006

32. Cardenas V, Abel S, Bowie CR, Tiznado D, Depp CA, Patterson TL, Jeste DV, Mausbach BT (2013) When functional capacity and real-world functioning converge: the role of self-efficacy. Schizophr Bull 39:908-916. https://doi.org/10.1093/schbul/sbs004

33. Braitman A, Counts P, Davenport R, Zurlinden B, Rogers M, Clauss J, Kulkarni A, Kymla J, Montgomery L (1995) Comparison of barriers to employment for unemployed and employed clients in a case management program: an exploratory study. Psychiatr Rehabil J 19:3-8

34. Westcott C, Waghorn G, McLean D, Statham D, Mowry B (2015) Interest in employment among people with schizophrenia. Am J Psychiatr Rehabil 18:187-207. https://doi.org/10.1080/15487768. 2014.954162

35. Macias C, DeCarlo LT, Wang Q, Wang Q, Frey J, Barreira P (2001) Work interest as a predictor of competitive employment: policy implications for psychiatric rehabilitation. Adm Policy Ment Health 28:279-297. https://doi.org/10.1023/a:1011185513 720

36. Jäckel D, Siebert S, Baumgardt J, Leopold K, Bechdolf A (2020) Patients' work-related participation impairments and need for support in day hospital and inpatient psychiatric treament. Psychiatr Prax 47:235-241. https://doi.org/10.1055/a-1112-5519

37. Knaeps J, Neyens I, van Weeghel J, Van Audenhove C (2015) Perspectives of hospitalized patients with mental disorders and their clinicians on vocational goals, barriers, and steps to overcome barriers. J Ment Health 24:196-201. https://doi.org/10.3109/ 09638237.2015.1036972
38. Hoffmann H, Kupper Z (2003) Predictive factors of successful vocational re-integration in patients with chronic schizophrenia. Psychiatr Prax 30:312-317. https://doi.org/10.1055/s-2003-42164

39. Cook JA, Blyler CR, Leff HS et al (2008) The employment intervention demonstration program: major findings and policy implications. Psychiatr Rehabil J 31:291-295. https://doi.org/10.2975/ 31.4.2008.291.295

40. Waghorn G, Lloyd C, Abraham B, Silvester D, Chant D (2008) Comorbid physical health conditions hinder employment among people with psychiatric disabilities. Psychiatr Rehabil J 31:243246. https://doi.org/10.2975/31.3.2008.243.246

41. Ang MS, Rekhi G, Lee J (2020) Vocational profile and correlates of employment in people with schizophrenia: the role of avolition. Front Psychiatry 11:856. https://doi.org/10.3389/fpsyt.2020. 00856

42. Tsang HWH, Leung AY, Chung RCK, Bell M, Cheung W-M (2010) Review on vocational predictors: a systematic review of predictors of vocational outcomes among individuals with schizophrenia: an update since 1998. Aust N Z J Psychiatry 44:495-504. https://doi.org/10.3109/00048671003785716

43. Rössler W, Ujeyl M, Kawohl W, Nordt C, Lasalvia A, Haker H, Hengartner MP (2019) Predictors of employment for people with mental illness: results of a multicenter randomized trial on the effectiveness of placement budgets for supported employment. Front Psychiatry 10:518. https://doi.org/10.3389/fpsyt.2019. 00518

44. Hampson ME, Watt BD, Hicks RE (2020) Impacts of stigma and discrimination in the workplace on people living with psychosis. BMC Psychiatry 20:288. https://doi.org/10.1186/ s12888-020-02614-z

45. Campbell K, Bond GR, Drake RE, McHugo GJ, Xie H (2010) Client predictors of employment outcomes in high-fidelity supported employment: a regression analysis. J Nerv Ment Dis 198:556-563. https://doi.org/10.1097/NMD.0b013e3181ea1e53

46. Volker D, Zijlstra-Vlasveld MC, Brouwers EPM, van Lomwel AGC, van der Feltz-Cornelis CM (2015) Return-to-work selfefficacy and actual return to work among long-term sick-listed employees. J Occup Rehabil 25:423-431. https://doi.org/10.1007/ s10926-014-9552-3

47. Sasaki N, Sato S, Yamaguchi S, Shimodaira M, Kawakami M (2018) Development of a scale to assess motivation for competitive employment among persons with severe mental illness. PLoS ONE 13:e0204809. https://doi.org/10.1371/journal.pone.0204809

48. Saavedra J, López M, Gonzáles S, Cubero R (2016) Does employment promote recovery? meanings from work experience in people diagnosed with serious mental illness. Cult Med Psychiatry 40:507-532. https://doi.org/10.1007/s11013-015-9481-4

49. Choi K-H, Fiszdon JM, Bell MD (2013) Beyond cognition: a longitudinal investigation of the role of motivation during a vocational rehabilitation program. J Nerv Ment Dis 201:173-178. https://doi.org/10.1097/NMD.0b013e3182848bd4 